\title{
A Ética da Metaestabilidade e a Direção Ética da Cĺnica
}

\section{The Ethics of Meta-Stability and the Clinical Direction}

\section{Resumo:}

Este artigo tem como objetivo problematizar a direção da ética clínica a partir de alguns impasses gerados em nossa prática cotidiana, pela exigência frequente na atualidade de formulação de diagnósticos e prognósticos precisos, que estabelecem a priori a direção do tratamento. Segundo G. Simondon e M. Foucault, a atitude ética desloca-se de uma concepção ética ligada a simples conformidade ou não aos códigos existentes, extraídos de verdades universais, para no lugar afirmá-la como invenção de novos modos de relação com os códigos. A proposta defendida por G. Simondon sobre a ética da metaestabilidade comparece para explicitá-la em seu caráter imanente. O sentido do ato ético não está dado numa instância transcendente, mas é inerente ao próprio ato, naquilo que ele é capaz de produzir, nos nexos que estabelece com o meio associado - esse sistema maior formado pelo homem e pelo mundo.

Palavras-chave: Clínica. Ética. Foucault. Simondon. Produção de subjetividade.

\section{Abstract:}

This article is intended to establish a discussion on the direction of clinical ethics, in the view of some impasses generated in our daily practice, and the need of formulating accurate diagnoses and prognoses which set, a priori, the direction of the treatment. According to G. Simondon and M. Foucault, the ethical attitude shifts from the mere compliance or non compliance with the existing codes, drawn from universal truths, to assert itself as an invention of new ways of relating to the codes. The proposal on the ethics of meta-stability advocated by G. Simondon aims at clarifying its immanent character. The sense of the ethical act is not given as a transcendental instance, but as inherent to the act itself, to everything that it is capable of producing, to the links it establishes with the associated environment - this larger system formed by the man and the world.

Keywords: Clinical direction. Ethics. Foucault. Simondon. Subjectivity.

TEDESCO, Silvia Helena; RODRIGUES, Cristiano. A ética da metaestabilidade e a direção ética da clínica. Informática na Educação: teoria \& prática, Porto Alegre, v. 15, n. 1, p. 159169, jan./jun. 2012.

\author{
Silvia Helena Tedesco \\ Cristiano Rodrigues \\ Universidade Federal Fluminense
}

$\sqrt{s}$ ste texto visa contribuir para a discussão sobre a ética que serve à orientação clínica das práticas "psi' na atualidade. Frente à problematização sobre ética, desenvolvida nas obras de Foucault e de Simondon, nossa preocupação maior será buscar, nestas concepções de ética, maneiras de desviar a clínica do perigo de recair no exercício do controle das populações e dos indivíduos (FOUCAULT, 2006). Ou seja, faremos o encaminhamento de algumas questões que poderão ajudar na remontagem da noção de ética, multiplicando possíveis encaminhamentos para o trabalho clínico.

Adiantamos que a ética de qualquer prática dirigida a um objeto - no nosso caso a subjetividade -, segundo Foucault, precisa ser pensada na relação imanente com este objeto. A ética clínica constrói-se na continuidade com a ética da subjetividade. $E$, na medida em que não existem objetos fixos e sim processos de subjetivação, a ética clínica se decide na consonância com tal movimento para incitar sua perseverança. Vejamos isso melhor. 
Este texto visa contribuir para a discussão sobre a ética que serve à orientação clínica das práticas "psi' na atualidade. Frente à problematização sobre ética, desenvolvida nas obras de Foucault e de Simondon, nossa preocupação maior será buscar, nestas concepções de ética, maneiras de desviar a clínica do perigo de recair no exercício do controle das populações e dos indivíduos (FOUCAULT, 2006). Ou seja, faremos o encaminhamento de algumas questões que poderão ajudar na remontagem da noção de ética, multiplicando possíveis encaminhamentos para o trabalho clínico.

Adiantamos que a ética de qualquer prática dirigida a um objeto - no nosso caso a subjetividade -, segundo Foucault, precisa ser pensada na relação imanente com este objeto. A ética clínica constrói-se na continuidade com $a$ ética da subjetividade. $E$, na medida em que não existem objetos fixos e sim processos de subjetivação, a ética clínica se decide na consonância com tal movimento para incitar sua perseverança. Vejamos isso melhor.

Apoiados nos últimos estudos foucaultianos expostos em trabalho anterior (RODRIGUES; TEDESCO, 2009), apresentamos a proposta inicial de definição de ética como atitude crítica de si mesmo, suscitada por situações incomuns da vida de um indivíduo ou comunidade. Trata-se de circunstâncias singulares em que as certezas de um julgamento anterior se mostram destituídas de valor resolutivo e, por esta razão, são interrogadas pelo impasse e exige a coragem de experimentar outros modos de ser. Consequentemente, podemos falar de acontecimentos que abrem uma brecha, uma distância irrecusável, problematizadora, entre aquilo que se é (atestado como insuficiente) e aquilo que se poderá vir a ser ( mas que ainda não somos), efetivada pela emergência de novos modos de viver.

Situações cotidianas cuja experiência comporta vetores resolutivos não fazem problema.
A questão ética se apresenta para a subjetividade em situações em que os balizamentos éticos já conhecidos, gerados em análises anteriores e que poderiam orientar a conduta atual, são interrogados e precisam dar lugar a tantos outros.

\section{Os impasses no plano de produção subjetivante e a prática clínica}

Na prática clínica observamos que nem sempre tais situações de impasse são experimentadas como problematização, de modo a mobilizar o plano das forças ou das qualidades afectivas ${ }^{1}$ que construiu e alimenta o impasse e que também carrega as condições deflagradoras das mudanças exigidas. Nessas ocasiões, a experiência, no lugar de ostentar a abertura ao seu ineditismo, fecha-se sobre o esgotamento do repertório de decisões e, atualizada como limite intransponível, só é capaz de ativar atitudes já desgastadas, mesmo que ineficazes à nova situação. Em outras, muito embora a insuficiência das atitudes já conhecidas seja considerada, a crise não é experimentada de modo potente, como oportunidade para instalação de processos inventivos. Uma vez aderido de modo excessivo aos territórios existenciais e aos seus códigos, o indivíduo segue insistindo na submissão às normas existentes e com isso repetições infindáveis tomam lugar, inapropriadas para lidar com a novidade da situação. Em outras ainda, a crise se instala, assim como a procura de outras formas de ação que, no entanto, podem acelerar-se excessivamente perdendo-se no puro movimento ou truncar-se no emaranhado de linhas-vetores presentes no plano da experiência. Constatamos, então, as mais diversas modalidades de desgovernos no pro-

1 Sobre as relações afectivas cf. Passos e Barros (2005). 
cesso. Seriam sobre estes desgovernos que a clínica visaria trabalhar. Neste momento nos vem a pergunta: que direção seguir na intervenção? Frente aos impasses, relatados como provocadores de sofrimento, caberia ao pensamento da clínica apontá-los, listá-los em diagnósticos?

Entre as muitas considerações traçadas sobre o esclarecimento de tais circunstâncias, poderíamos citar as que procuram, na figura subjetiva, a razão para as interrupções e lentificações, mas nosso interesse é outro. Não negamos que tais balizamentos são também pertinentes, mas é preciso refletir sobre os perigos, já muitas vezes assinalados por Foucault, de avançarmos muito nossa análise na direção das classificações, da elaboração de tipologias normalizadoras.

É tentador e bastante solicitado em nossas práticas clínico-institucionais a realização de diagnósticos, classificações psicopatológicas, prognósticos e protocolos clínicos precisos. Porém, qual o preço de nos tranquilizarmos com o saber clínico que prioriza a previsibilidade na clínica? O que perdemos com a dedicação exclusiva à classificação dos modos truncados de subjetivação?

Lembremos que a preocupação exagerada por diagnósticos pode também levar a cegueira. Implica no risco de construir uma clínica que, acima de tudo, privilegie a negatividade do processo em jogo. Frente ao risco de reforçar linhas endurecidas e cristalizadas, lembramos a importância de seguir outra direção. Muitas teorias clínicas, desde Freud (1976 [1916])², assinalaram a positividade dos sintomas como signos quase invisíveis e quase inaudíveis, que carregam em si, um duplo encaminhamento. Nesta mesma direção, Guattari e Rolnik (1993) nos advertem que o sintoma é como o vôo do

2 Conferir, sobretudo, a noção de formação de compromisso em Freud (1976 [1916]). pássaro que bate no vidro da janela. No vôo do pássaro, que não nos atraia especialmente o bater no vidro, o bloqueio do movimento, a insuficiência do cálculo. No lugar do sentido de fracasso relancemos a cena à sua trajetória, a potência do movimento, ainda em germe, mas presente.

Vários são os modos de desgoverno, é certo, mas estes estão atados a particularidades de cada história, de cada vôo particular. As dificuldades, ou seja, as lentificações, paradas ou velocidades excessivas serão consideradas, mas tenhamos o cuidado de não as isolarmos do seu plano de produção. É só na conjugação com os jogos entre diferentes vetores de força que o movimento pode se apreendido, deixando ver os impasses, não como paralisações absolutas e sim como componentes da trajetória existencial aí esboçada.

Retornemos, portanto, ao vôo, ao movimento. Interessa detectar as modalidades de vetores que compõem a paisagem movente da subjetividade, o plano das forças em jogo no contexto da experiência, nas quais os impasses estão atrelados.

\section{A dimensão moral e a direção ética em M. Foucault}

Primeiramente, lembramos que tanto os termos moral quanto ética se ampliam para além do modo de compreensão corriqueira. Foucault (2004 [1984]) nos lembra que o domínio da moral não diz respeito simplesmente à adequação de nossos atos a códigos, ele afirma que esse domínio recobre o intervalo entre o sujeito e o código, ou seja, diz da relação do sujeito aos códigos. Ele se define pelas infinitas modalidades de relação que o sujeito da ética é capaz de produzir. Dentro do contexto da moral, a ética apontará para determinada direção assumida por estas relações. Percebe-se que a questão da moral e a da éti- 
ca, a ela ligada, ao não se referir à simples conformidade ou não a códigos existentes, também deixa para trás a preocupação em mostrar consonância com verdades universais sobre a natureza do sujeito ou da natureza da ordem social. Note-se que estão aqui incluídos os códigos explícitos ou implícitos, formalmente elaborados ou apenas existentes ao nível dos acordos, convenções. Apesar dos códigos se apresentarem em diferentes graus de formalização, seus processos de emergência e construção estão apoiados, em última instância, em verdades científicas ou filosóficas, geradoras, através deles, de modelizações normalizadoras dos indivíduos e populações (FOUCAULT, 2006).

A questão se amplifica quando entendemos que o domínio da moral compõe um plano maior de forças marcado por forte heterogeneidade. Em seus embates, os vetores tendem a duas direções distintas e articuladas. Numa delas, a tendência é de convergência, de redundância, que, sem jamais atingir unidades, faz ver e dizer tudo aquilo que tomamos como realidade. Na outra, ocorre a equivocação desta tendência, abrindo o plano a trajetórias ainda desconhecidas (TEDESCO, 2007).

Neste jogo de forças, entre os inúmeros vetores que participam, compondo e descompondo arranjos, Foucault sublinha quatro conjuntos de vetores, quatro aspectos envolvidos no domínio da moral e da ética, a saber: substância ética, modos de sujeição, teleologia e prática de si. Os modos de subjetivação viabilizam ao indivíduo posicionar-se na relação com as normas, configurando escolhas: sobre o quê na sua vida, que parte de si próprio, servirá de objeto sobre o qual recairá a ação moral (substância ética); sobre o motivo pelo qual ele se deixa afetar pelo preceito (modo de sujeição); sobre o 'modo de ser' almejado, que lhe servirá como rumo para realização moral (teleologia); sobre que práti- cas Ihe permitirão, por exemplo, se conhecer, governar-se, transformar-se a fim de atingir o telos visado, ou seja, atividade formadora do si mesmo ou práticas de si (FOUCAULT, 2004 [1984]). Nesta direção, a atitude ética resulta dos vetores que atravessam esses quatro aspectos, ela é resultante do conjunto de circunstâncias nos quais os códigos assim como o sujeito estão incluídos, mas sem ocuparem o centro da cena. O gerenciamento destes quatro aspectos decide a direção ética ou não dos modos de subjetivação, de modo que os códigos deixam o lugar prioritário de comando. "A regra não desaparece, mas em vez dela se impor ao sujeito, este [ato ético] se a dá em função de uma certa arte de viver, de uma estilística da existência" (EWALD, 1984, p. 73). A avaliação da justeza dos códigos morais existentes não é mais suficiente, ao mesmo tempo em que a atitude ética não é pensada como emanando do subjetivismo, decorrente de livre arbítrio e/ou da escolha voluntária tecida por uma consciência clara a si. A atitude ética resulta das condições heterogenéticas, da configuração do plano de forças convergentes e divergentes, atuantes num dado momento.

O tema da ética em Foucault, apesar de só ter ganhado relevância nos seus últimos escritos e cursos, sempre esteve presente em seu percurso, implícita nos seus estudos sobre subjetivação, em especial, na análise da relação que os indivíduos estabelecem com as estruturas políticas e sociais. Interessouse pela constituição dos sujeitos nos jogos de verdade, nas relações de força, presentes nos planos do saber/poder, que tornavam possível aos homens experiências que os levavam a se reconhecerem, a se verem e se construírem como sujeitos em suas classificações como loucos, delinquentes, perversos entre outras. Essas classes surgem referidas a verdades filosóficas, científicas ou religiosas que nos ofe- 
recem, nessas categorias, a nossa verdade e, portanto, sugerem o que somos e, consequentemente, nos impõe o modo como precisamos nos conduzir. Do saber nascem prescrições, normalizações da vida. Foucault, nos advertiu de que as verdades produzidas instituem códigos prescritivos, normalizadores universalizantes, face aos quais a subjetivação é produzida como efeito (FOUCAULT, 1979).

Porém, mais avante em suas pesquisas, a partir da História da sexualidade I (FOUCAULT, 1977), o tema da ética aparece articulada ao domínio da moral. Este novo componente da moral não expressa exclusivamente modos de submissão às normas, formas de assujeitamento na produção de si que daí decorrem. Em função do caráter mais ou menos indeterminado, do solo poroso em relação às normas que esta experiência pode assumir, dois encaminhamentos são cogitados. Ou seja, sublinha-se que a composição a ser construída entre subjetividade e norma pode variar de acordo com o tipo de conectividade, com as composições de forças em jogo no momento. Essas duas direções dizem ambas do processo de construção do sujeito moral. Na relação com à norma existe outra possibilidade para a subjetividade, diferente dessas situações em que os códigos são como mandos absolutos e que circunscrevem apenas opções de obediência ou pura desobediência a ela. Paralelo à relação centrada no código, que resulta na subjetividade como assujeitamento, aparecem relações de problematização inventiva, da equivocação das identidades e da consequente deriva dos processos de subjetivação. No primeiro caso, trata-se do sujeito jurídico, produzido na submissão ao código. No segundo, falamos do o sujeito ético, relativo ao processo de invenção de si. A clínica assumiria como direção ética instigar a produção do sujeito ético, ou seja, os modos éticos de subjetivação.

\section{Clínica e o sujeito ético}

Percebemos que o processo de subjetivação está recoberto pelo domínio da moral, ocupado pelas relações entre o indivíduo e as normas. E aqui esbarramos com outra questão - a do governo dos outros e do governo de si mesmo. A experiência na clínica vai integrar ambas formas de governo. Vejamos rapidamente cada uma delas. Por exemplo, a investigação do governo dos outros, trabaIhada por Foucault nos textos sobre história da loucura (FOUCAULT, 1978), revelou que a questão passava pela história da produção do conjunto de normas que, ao permitir lidar com a loucura, produzia na realidade, linhas de corte que serviam à distinção e à classificação que legitimava a separação entre loucos e não loucos. Ou seja, vemos aí que o saber sobre o sujeito instituía princípios normalizadores. Um mesmo conjunto de normas é generalizado para todos e autoriza identificar os indivíduos, classificando-os nessas duas categorias homogeneizantes.

Já nas investigações desenvolvidas a partir dos estudos da História da Sexualidade I (FOUCAULT, 1977), aparece a noção de governo de si articulado ao tema do governo dos outros. A ênfase agora recai sobre estratégias do saber/poder, não apenas como modo de controle sobre os outros, mas também como controle, gerenciamento, exercido pelo indivíduo sobre si mesmo. A experiência de si é entendida como governo de si e se realiza numa certa relação com o governo dos outros. Porém, existe a possibilidade de o processo advir atitude ética, ou seja, as normas, que a princípio fazem ver, dizer e tratar, e neste procedimento, produzir o outro como louco, neurótico, perverso e assim por diante, podem passar a servir à montagem da própria experiência de si como a atitude crítica de si. As normas, agora, incluem-se no saber que 
o indivíduo elabora sobre si mesmo: atitudes, afetos, condutas. Enfim, as verdades científicas e filosóficas constroem valores normativos, mas, agora eles serão regulados pela experiência de si mesmo (FOUCAULT apud EWALD, 1984). Ou seja, as normas não são absolutas na produção dos sujeitos e passam a funcionar como componentes entre outros, podendo, inclusive, ser interrogadas, desacreditadas. Enfatiza-se assim, a direção ética como estratégia prática que, em vez de transformar os elementos existenciais distintos em uma unidade homogênea, tem por função estabelecer quais são as possíveis conexões entre os termos díspares, mantendo-os, entretanto, na disparidade. "A lógica da estratégia, é a lógica da conexão do heterogêneo e não a lógica da homogeneização do contraditório". (FOUCAULT, 2004 [1984], p. 44).

A novidade é que a experiência vivida no jogo de forças heterogêneas comporta abertura à própria dissolução dos pontos de vista deste si mesmo. Existe aí oportunidade de a experiência equivocar os critérios normalizadores envolvidos e propor, no conjunto dos nexos que a constituem, outras direções para o processo de subjetivação.

Neste ponto, duas questões relevantes se colocam. Uma delas diz respeito à avaliação das normas como formas de controle, tendências à homogeneização que comprometeriam o movimento das forças, uma vez que este é alimentado pela relação entre componentes díspares. Com isso, elas dificultariam a promoção de processos de subjetivação ética. A partir daí poderíamos ter a falsa compreensão de que os códigos, sendo contrários à direção ética da subjetivação, precisariam ser eliminados por este processo e assim seriam estimuladas atitudes opositivas, de combate aos códigos. O estimulo à subtração dos códigos, isto é, à eliminação das regulações que sustentam determinada ordem de fatos, nos leva a uma outra questão. Nesse quadro, a experiência de subjetivação ética estaria voltada somente à dissolvência dos pontos de vista, dos posicionamentos do si mesmo. E que, portanto, a subjetivação se restringiria a movimentos de deriva, deixando pensar que a ética, neste caso, incitaria, exclusivamente, instantes de passagem, movimentos ininterruptos de dissipação dos modos de subjetivação, sem sedimentação numa forma, mesmo que temporária. $\mathrm{E}$, consequentemente, perguntamos: estaria a aposta clínica focada no deslocamento infindável de nós mesmos? É para o esclarecimento desta questão que comparece a noção de ética da mestaestabilidade em Simondon.

\section{Simondon e a ética da metaestabilidade}

Como Didier Debaise (2002) indica, a noção de sistema aplicado à processualidade do ser, desenvolvido por Simondon, supõe, na base, "uma relação entre elementos heterogêneos, produzindo uma organização imanente..." (DEBAISE, 2002, p. 60). Trata-se de um conjunto de elos formado pela tensão existente entre os integrantes de cada situação. Ou seja, de início, da relação de disparidade entre os componentes emerge uma energia potencial, um plano relacional como condição para a segregação de certos conjuntos que então se destacam do plano maior de diferenças potenciais, dando a ver o contorno de uma forma destacada, individuada. A partir daí, podemos conceber dois modos de funcionamento distintos, mas interligados, que alimentam à vitalidade do sistema.

O princípio energético se baseia no contato entre duas dimensões distintas mas interdependentes, reforçando a idéia de reciprocidade. São duas dimensões do ser: o individuado e o pré-individual. O ser seria definido por 
processos reiterados de constituição, isto é, um processo de engendramento a partir do contato entre duas dimensões díspares. Uma corresponderia à dimensão do individuado, à realidade marcada pela tendência à repetição de si e, portanto, reconhecida por regularidades facilmente delimitáveis. A outra dimensão seria a do pré-individual, constituída por pontos singulares, isto é, por puras diferenças potenciais, alheias à ordenação. Enquanto a dimensão do individuado ostenta aparente contorno e certa homogeneidade interna, esta outra, a do pré-individual, é caracterizada justamente pela inexistência de limites e por sua dissimetria. Ocasiões de desestabilização, dissolvências, coexistem com fases de conservação, regularidades, indispensáveis a atualização efetiva de novas realidades. Nessa direção, a ética assume o sentido da sinergia estabelecida entre as individuações sucessivas, cada uma delas marcadas por simetrias, frequências, próprias à dimensão individuada. Esta composição expressa o sentido ético da individuação. Importa notar que ele emerge do próprio ato, nas circunstâncias locais que o acompanham e o definem. Como nos esclarece Escóssia (2003): "este sentido [do ato] não está dado numa instância transcendente ao ato, mas no próprio ato, naquilo que ele é capaz de produzir, na relação que ele estabelece com o meio associado - este sistema maior formado pelo homem e pelo mundo" (ESCÓSSIA, 2003, p. 182-183). Vale também assinalar que a rede aqui instalada se distingue de um simples encadeamento de atos, como sucessão de ocorrências independentes. A ética que interessa é a das relações entre heterogêneos. O sentido ético expressa a ressonância, o trabalho exercido na relação de disparidade de um ato sobre o outro, sem entanto desprezar as fases individuadas. É na relação entre individuado e o pré-individual que ambos se recompõem e reestabelecem fronteiras e, com estas também é delineado o que lhes escapa, redesenhando a amplitude de cada um dos dois planos, assim como a dos devires.

Cada ato ético implica necessariamente sua integração heterogenética com outros atos. Não existem regiões isoladas, ilha perdidas, ou seja, atos fechados sobre si, o sentido ético define-se simultaneamente, como exterior e interior ao ato. Ao mesmo tempo, o ato ético estabelecido em rede segue direções infinitas, equivocando os sentidos tradicionalmente atribuídos às conexões internas às estruturas, como a horizontalidade e a verticalidade. As conexões se fazem segundo as condições específicas da rede a cada momento, conferindo imprevisibilidade às soluções encontradas (ESCÓSSIA, 2003).

Simondon não crê, portanto, numa definição fechada de ética ou moral ${ }^{3}$ na medida em que ela, como qualquer outra forma conceitual ou empírica, jamais poderá ser circunscrita completamente. Sua proposta é lançar as bases para a ética da processualidade própria à individuação. A ética, portanto, é definida como "o sentido da individuação, o sentido da sinergia das individuações sucessivas" (SIMONDON, 1989, p. 242).

Sua concepção ética parte da critica às duas concepções de ética - a ética pura e a ética aplicada - que estariam ambas apoiadas numa mesma axiomática lógica da estabilidade, do absoluto incondicional.

A ética pura diz do ser imutável, "definido como um e completamente dado na substância individualizada" (SIMONDON, 1989, p. 236), enquanto a ética prática ou aplicada fala da perpétua variação, do ininterrupto movimento que marca as paixões, a servidão, o vício, a existência. Vemos as duas realidades dicotomizadas, de um lado o ser eterno e de

3 Para Simondon os termos ética e moral se equivalem. Cf SIMONDON, 1989). 
outro as corrupções da vida. A ética prática, nesse ponto de vista, se constitui na oposição à ética da substância, na contraposição entre o ser eterno e a vida em devir. A vida se desdobraria em torno de ser, não Ihe pertencendo e nem o modificando na sua essência, de maneira que ficaria assegurada sua estabilidade. Segundo Simondon, as duas éticas seriam insuficientes para dar conta do processo de individuação do ser, uma vez que ou temos a fixidez completa ou o puro movimento sem lastro, sem permanência, sem atualização efetiva de seus efeitos. É preciso buscar outras composições entre instantes de maior fluidez e períodos de constância relativa, aliar os instantes de passagem com certa conservação, necessária para instauração de realidades. Como compor instabilidade e estabilidade? Por esta razão o autor propõe substituir a dicotomia entre ética do ser e a ética do puro fluxo pela ética cujo sentido aponta para o ser como série sucessiva de estados de equilíbrio metaestável (SIMONDON, 1989). É essa ética da metaestabilidade que nos interessa.

Distantes de encontrar identidades entre Simondon e Foucault ou buscar esclarecimentos de um autor no outro, apostamos na oportunidade de utilizar a concepção de ética metaestável para sublinhar alguns aspectos, já presentes no pensamento foucaultiano, que auxiliam a melhor compreensão de nossa questão. A proposta é recorrer à Simondon, mais precisamente à sua concepção de ética, a fim de justificar a articulação entre estabilidade e instabilidade, entre forma e movimento, como maneira estratégica de esclarecimento da ética da clínica, voltada ao processo de subjetivação que, se não a afirma como substancialidade também não se interessa por aprisioná-la num processo de variação vazio e incessante. A pura fluidez não serve de direção à clínica que buscamos.

\section{A ética da clínica: a condição metaestável da subjetivação}

Na composição entre Foucault e Simondon propomos a ética da processualidade do si. $\mathrm{O}$ absoluto incondicional sai de cena nas suas duas formulações: seja na forma completa e definitiva, seja no puro movimento. A direção se cumpre na produção de diferentes modos individuados de ser, no acompanhamento desse processo contínuo de gênese de formas (SIMONDON, 1989).

Neste processo, as prescrições normativas funcionam tal como os princípios reguladores de cada fase individuada que não se querem absolutos e nem podem ser abolidos sob o risco de o processo transformar-se numa sucessão infinita, onde nenhuma norma possa valer.

De modo que a ética não orienta a prática clínica à procura de um estado a atingir e nem à fluidez completa, mas ao exercício de composição. Neste, as normas instituídas não se dão como fatores de homogeneização, mas como componentes de práticas de liberdade, uma vez que é no jogo de liberdade e de transmutação das normas que novos modos de ser terão lugar. Daí dizer que as normas não se opõem à liberdade, visto que existem também como matéria de uso singular. Vale desconsiderar a prioridade conferida a uma única norma ou a um único conjunto delas para, no lugar, reconhecer a metaestabilidade das próprias normas.

Podemos, neste momento, explicitar a modalidade de experiência que mobiliza a atitude ética da seguinte maneira: quando a experiência expõe seu viés crítico, questionando e inviabilizando todo o repertório de ações disponibilizadas, a problematização, aí exposta, dá lugar à busca pela invenção de novas relações com o código e, por conseguinte, faz avançar o processo de subjetivação na direção ética. $A$ clínica acompanha e incita a subjetividade na 
direção de sua essência inventiva. Ela orienta a procura de modos inéditos de experimentar e agir junto à norma. Ou seja, cuida para que a subjetividade não se deixe produzir simplesmente em consonância com as normas ou contra elas, mas descobrir seus poros, dobras e vieses a fim de operar transvasamentos e, desse limiar entre a obediência e desobediência, instaurar modos de agir imprevistos que interroguem não só as duas opções como também as próprias normas ali em jogo. Portanto, podemos dizer que os processos de subjetivação seguem duas direções possíveis. Consideradas ambas como da ordem da experiência moral, elas expõem sua dupla natureza: a de conduzir à atitude de submissão ao código, própria ao sujeito jurídico - e a tendência a por em questão o código e, na relação inventiva com ele, propor outra realidade moral.

Neste caso, constatamos que práticas de sujeição, de adequação aos códigos vigentes, na verdade, não se incluem na prática clínica. Uma vez que clínica se define como klinamem, ela é provocadora de desvios na rota existencial. Ela pratica a ética em seu viés de ruptura e desconcerto (BAREMBLIT, 1998, PASSOS; BARROS, 2001). É nesse sentido que o ato clínico efetiva-se nos desvios de rota, nos deslocamentos do indivíduo de sua trajetória já familiar, na direção da invenção de outros modos para o si e para as normas. Esta segunda direção comporta a noção foucaultiana de liberdade, de sujeito ético, ou seja, do uso singular das normas na direção da criação de si e de mundos.

É na oportunidade de criar condições de problematização das normas, produtora dos indivíduos, que a clínica se encontra com a política e pode ser considerada como prática de liberdade (TEDESCO; RODRIGUES, 2009). Ela cuida para que o sofrimento não vigore em sua completa negatividade, de modo que a crise que o habita não nos conduza a práticas de reabilitação, mas acompanhe a subjetividade nessa experiência crítica a fim de reanimar o movimento, e em especial, a trajetória ali esboçada.

Se é na sua relação com o código que o sujeito moral (ético ou jurídico) constitui-se, cabe a clínica privilegiar essa relação. Para tal, precisamos remeter os impasses do sujeito ao plano de produção que os engendrou e os alimenta, para acompanhar o funcionamento do diagrama, das relações de poder com seus preceitos: seja como regulação dos corpos individualizados pelo poder disciplinar, seja como linhas de corte das distribuições organizadoras da população pelo biopoder. Uma vez, juntos, habitantes destas linhas de força, vale ficar a espreita dos instantes críticos, no momento em que as normas podem ser problematizadas, oportunizando modos outros de existência ainda não experimentados. É função da escuta clínica detectar esses instantes de bifurcação do processo e trabalhar, na relação com o sujeito, na direção de novos encaminhamentos para sua trajetória.

As normas, sabemos, vigoram na vida cada vez mais insistentemente. Vivemos sob a forte pressão moral do contemporâneo, na qual proibições e princípios reguladores desenvolvem novos modos de controle mais abrangentes, não mais restritos a instituições, mas espalhados nos espaços abertos da sociedade da comunicação: redes cibernéticas, telefônicas conectam todos nós, não importa onde estejamos, para nos ofertar cada vez mais preceitos. No entanto, a estratégia não reside em sublinhá-los como bloqueios absolutos ao movimento, vinculando liberdade à abolição dos códigos. A clínica como prática de si orienta a aposta na porosidade da relação que podemos construir com a norma, de modo a detectar outras rotas, tanto para a subjetividade quanto para o código. Face ao código, precisamos ser convocados à experiência de problemati- 
zação, ou seja, como instaurar, no interior do próprio regime normalizador, outros modos de regulação mais condizentes com a vida, com o movimento que nos é inerente?

Interessa à clínica examinar modos possíveis de reinvenção das normas, pois se elas modelam, também podem inspirar movimentos, desvios e composições. Se não interessa a simples obediência ou desobediência que deixa a norma intacta, também pouco representa o total abandono do código. A delicadeza do processo criador nos exige mais. Habitemos o plano da norma, não para cair no seu jogo, mas inventar outros jogos, descobrir seus vieses, suas margens e limites para propor sua reinvenção.

Nesse sentido, a experiência limite, a experiência de crise, subjacente aos impasses subjetivantes, não deve ser eliminada, mas acompanhada para efetivamente se realizar como limiar de passagem a outras modalidades de norma e modos de ser $\mathrm{O}$ valor negativo geralmente atribuído às experiências de desestabilização, de crise desaparece. Como ressalta Neri (2005), a experiência atual da falência dos valores e de preceitos já estabelecidos não se configura numa patologia do contemporâneo, num entrave à ordem a ser superado ou controlado por códigos ainda mais restritivos. E acrescentamos que, diferentemente, a crise precisa ser afirmada como condição necessária para a experiência ética, como atitude crítica, própria aos modos de subjetivação e garantia de sua processualidade.

$\mathrm{Na}$ parceria com Foucault e Simondon, entendemos que ética não deve ser compreendida como substância, mas como um exercício cuja efetivação envolve o aparecimento de configurações inéditas para o si mesmo e para o mundo. Na relação com as prescrições, a experiência ética nos oferece, no lugar do assujeitamento, a problematização do preceito, a provocação de desvios, de diferentes encaminhamentos para nossos modos de ser, experimentar e de agir. Não abandonar as normas, mas reutilizá-las. Frente à norma, nem normalizados, nem juízes normalizadores, mas inventores que reconduzem os códigos e a nós mesmos ao movimento que nos é, a todos, inerente.

\section{Referências}

BAREMBLIT, G. Introdução à esquizoanálise. Belo Horizonte: Biblioteca do Instituto Félix Guattari, 1998.

ESCOSSIA, L. Por uma ética da metaestabilidade na relação homem-técnica. In: PELBART, P.; COSTA, R. (Org.). O Reencantamento do concreto. Cadernos de subjetividade. São Paulo: Ed. Hucitec, 2003.

EWALD, F. Michel Foucault In: ESCOBAR, C. H. (Org.). Dossier/ Últimas Entrevistas. Rio de Janeiro: Taurus, 1984.

FREUD, S. Conferência introdutórias sobre psicanálise. Edição standard brasileira das obras completas de S. FREUD, volume XVI. Rio de Janeiro: Imago, 1976 [1916].

FOUCAULT, M. História da sexualidade I, Rio de Janeiro: Graal, 1977. 
FOUCAULT, M. História da loucura. São Paulo: Ed. Perspectiva, 1978.

FOUCAULT, M. Microfísica do poder. Rio de Janeiro: Graal, 1979

FOUCAULT, M. A ética do cuidado de si como prática da liberdade. In: BARROS DA MOTTA (Org.) Ética, sexualidade e política. Coleção "Ditos e Escritos", Vol. V. Rio de Janeiro: Forense Universitária, 2004 [1984].

FOUCAULT, M. Seguridad, território, populación. Cours ao Collège de Frence, (1977-1978) Édición estabelecida por Michel Senellart, bajo La dirección de François Ewald e Alessantro Fontana. Traducción Horacio Pons. 2006.

NERI, R. Enfraquecimento da lei ou aumento do poder punitivo? Uma reflexão acerca do discurso psicanalítico sobre a crise do simbólico na contemporaneidade In: TEDESCO, S.; NASCIMENTO M. L. (Org.). Ética e Subjetividade: novos impasses no contemporâneo. Porto Alegre: Sulinas, 2009.

PASSOS, E.; BARROS, R. Passagens da clínica. In: MACIEL, A.; KUPERMANN, D.; TEDESCO, S. Polifonias: Clínica, política e criação. Rio de Janeiro: Contracapa, 2005.

PASSOS, E.; BARROS, R. B. Clínica e biopolítica na experiência do contemporâneo. Psicologia Clínica PósGraduação e Pesquisa (PUC/RJ), PUC-RJ, v. 13, n. 1, p. 89-99, 2001.

RAJCHMAN, J. Eros e verdade: Lacan, Foucault e a questão da ética. Rio de Janeiro: Jorge Zahar , 1993.

RODRIGUES, R.; TEDESCO, S. Por uma perspectiva ética das práticas de cuidado no contemporâneo In: TEDESCO, S.; NASCIMENTO, M. L. Ética e Subjetividade: novos impasses no contemporâneo. Porto Alegre: Sulinas, 2009.

ROLNIK, S.; GUATTARI, F. Micropolíticas: Cartografias do desejo. Petrópolis: Vozes, 1993.

TEDESCO, S. Subjetividade e seu plano de produção. In: QUEIROZ; CRUZ (Org.). Foucault, hoje? Rio de Janeiro: 7 Letras, 2007.

Recebido em: 27 de maio de 2012

Aprovado para publicação em: 13 de junho de 2012

\section{Silvia Helena Tedesco}

Professora do Programa de Pós-graduação em Psicologia do Departamento de Psicologia da Universidade Federal Fluminense e orientadora da dissertação de mestrado da qual foram extraídas informações para este artigo. Niterói/RJ, Brasil. E-mail: shtedesco@gmail.com

\section{Cristiano Rodrigues de Freitas}

Mestre em Psicologia pelo Programa de Pós-graduação em Psicologia da Universidade Federal Fluminense. Cristiano. Niterói/RJ, Brasil. E-mail: rodrigues@ig.com.br 